\title{
Concrete use of the joint coordinate system for the quantification of articular rotations in the digital joints of the horse
}

\author{
Christophe Degueurce ${ }^{\text {a*}}$, Henry Chateau ${ }^{\mathrm{a}}$, \\ Viviane PAsqui-BoutArd ${ }^{\mathrm{b}}$, Philippe PourCelot ${ }^{\mathrm{a}}$, Fabrice Audigié ${ }^{\mathrm{a}}$, \\ Nathalie Crevier-DenoIX ${ }^{\mathrm{a}}$, Hassen JERBI ${ }^{\mathrm{a}}$, Didier GEIGER $^{\mathrm{c}}$, \\ Jean-Marie DENOIX ${ }^{\mathrm{a}}$ \\ a UMR INRA-DGER Biomécanique du Cheval, École Nationale Vétérinaire d'Alfort, \\ 94704 Maisons-Alfort Cedex, France \\ ${ }^{\mathrm{b}}$ Laboratoire de Robotique de Paris, Université Versailles-Saint Quentin en Yvelines, \\ 78140 Vélizy, France \\ c Laboratoire de Mécanique Physique, CNRS UPRES-A 7052, Université Paris XII Val de Marne, \\ 94000 Créteil, France
}

(Received 9 February 1999; accepted 21 December 1999)

\begin{abstract}
A method is detailed allowing the computation of three-dimensional (3D) joint angles. Each joint of the equine digit is modelled as a sequence of three single axis rotary joints. The Joint Coordinate System was used; it involves a specific sequence of cardanic angles. The decomposition of the angles was chosen so that the three elementary angles coincide with the flexion/extension, passive abduction/adduction and lateral/medial rotations. The algorithms and kinematic procedures were described for the equine front digital joints. This method was tested in vitro on four forelimbs. For each limb, angle values were measured while the member was loaded by a press (from 500 to $6000 \mathrm{~N}$ ). These tests were repeated while a wedge raised one part of the hoof (toe, heel, lateral and medial sides) in order to induce modifications of the angular patterns of the joints. This method allowed a precise quantitative determination of $3 \mathrm{D}$ joint movements. The modifications occurring with the wedges are clearly identified and confirm some previously published semi-quantitative observations. Moreover, this method provides a way to collect objective data on the functional anatomy of joints and could be used to study connective shoeing thoroughly. It may be directly applied to other species and may be used by researchers interested in discreet articular movements, especially occurring in other planes than the sagittal one.
\end{abstract}

horse / kinematics / digital joint / joint coordinate system / cardanic angles

* Correspondence and reprints

Tel.: (33) 1439670 52; fax.: (33) 1439631 62; e-mail: degueurc@ vet-alfort.fr 
Résumé - Utilisation concrète du système de coordonnées articulaires pour la quantification des rotations des articulations du doigt du cheval. Cet article détaille une méthode permettant la mesure des trois composantes anatomiques, en rotation, du mouvement des articulations du doigt du cheval. Ce mouvement a été modélisé par une séquence de rotations autour de trois axes selon le Joint Coordinate System ; les trois angles élémentaires correspondaient aux mouvements de flexion/extension, d'adduction et abduction passifs et de rotations latérale et médiale de l'articulation. Les algorithmes et les procédures de mesure cinématique sont décrits et appliqués aux articulations du doigt antérieur du cheval. Cette méthode a été testée in vitro sur quatre membres thoraciques. Pour chacun, les valeurs des trois angles ont été mesurées durant la mise en charge du membre (de 500 à $6000 \mathrm{~N}$ ). Ces tests ont été répétés en élevant alternativement certaines parties du sabot (talons, pince, quartier latéral, quartier médial), de façon à modifier les décours angulaires des articulations du doigt. Cette méthode a permis de mesurer précisément les 3 composantes anatomiques, en rotation, du mouvement articulaire. L'incidence de l'élévation de différentes parties du sabot sur les angles articulaires digitaux a été étudiée ; elle confirme les résultats précédemment acquis par des méthodes semi-quantitatives (radiographie, surface de contacts articulaires). Cette méthode peut être utilisée pour l'étude de l'influence des ferrures orthopédiques sur le comportement des articulations du doigt du cheval. Par ailleurs, elle n'est pas spécifique du cheval mais est directement applicable aux autres espèces animales. Elle peut être mise en œuvre par les chercheurs soucieux de mesurer des phénomènes articulaires plus discrets que la flexion dans le plan sagittal.

cheval / cinématique / articulation du doigt / système de coordonnées articulaires / angles cardaniques

\section{INTRODUCTION}

The description of the articular movements of joints is an important subject in anatomy, semiology and diagnosis. Horses are especially interesting in this field of research because the equine digital joints are sites often affected by locomotor diseases. They undergo very high stresses during locomotion, particularly during uneven foot bearing [25]. These joints are quite specialised in flexion/extension movements occurring in the sagittal plane but they may also undergo axial rotations and collateromotions. The term of collateromotion describes a passive rotation in the frontal plane, a lateromotion being a displacement of the distal segment in a lateral direction relative to the proximal one and a mediomotion, its contrary [26]. These axial rotations and collateromotions are small amplitude movements which are incriminated by clinicians for the generation of articular pain and joint damage [31]. As an example, the symptoms of lameness due to interphalangeal osteoarthrosis increase as a horse is running a curve $[17,27,38]$. This is related to the strong influence of the asymmetrical hoof placement on the floor [26] and many authors consider the mediolateral imbalances of the foot as a favouring or activating factor of several osteoarticular diseases [6, 13, 24, 47, 53].

Considering the number of clinical applications such as orthopaedic hoof trimming and shoeing, the behaviour of the equine digital complex was evaluated using several techniques. Radiographic studies provide an objective evaluation of flexion and extension in the sagittal plane with lateromedial views $[10,22,23]$ or collateromotion with dorsopalmar views [23]. But this bi-dimensional (2D) method is restricted to an instantaneous measurement and is less sensitive to small axial rotations. Another commonly used radiographic technique for small measurement in human biomechanics is the three-dimensional (3D) Roentgen stereophotogrammetry [44]. Radio-opaque balls are inserted into each segment and radiography is performed before and after each motion step. It allows 3D measurements but does not provide a continuous dynamic measurement. 
A technique based on coloured articular surfaces has also been developed in vitro for equine research [23]. Because its sensitivity detects axial rotation and passive adduction/abduction movements in the digital complex, it is used to qualitatively evaluate the influence of hoof balance and stance modifications on the movements of the digital joints.

Three-dimensional goniometry is currently used in human biomechanics. It provides a way to detect the 3 components of an articular movement [14, 33, 35, 48]. Unfortunately, this technique cannot be easily applied to the horse even if $2 \mathrm{D}$ goniometry is useful for the sagittal movements [42].

In vivo studies have also involved the measurement of the sagittal components of the equine limb joint angles using kinematics [5]. Unfortunately, the precision of these results for the distal joints is often poor because it is very difficult to stick skin markers accurately on the bony prominences of the second phalanx. The small size of this bone limits the possibility to study both interphalangeal joints simultaneously and a so-called resultant interphalangeal joint made of the composition of two real ones has to be considered [21]. The relative motion between the skin and bone also limits the accuracy of such measurements.

Kinematics provides an easy way to collect 3D coordinates of markers linked to the bones. Different mathematical models associated with kinematic measurements have been proposed for the quantitative evaluation of human locomotion [3, 41, 52]. Because the subject is of high interest and necessitates standardisation, the International Society of Biomechanics recommends the use of the Joint Coordinate System (JCS) [55] described by Chao [14] and Grood and Suntay [30]. It provides a precise mathematical description of clinical terminology for joint rotational motions [29]. Until now, this technique has never been used in equine research although a number of clinical applications may be available in this species. The ground for this lack of research is certainly the difficulty for biologists to use these mathematical procedures.

Thus, the purposes of this study were:

- to apply the technique of the Joint Coordinate System to the digital joints of the thoracic limbs of horses in vitro, thus realising the simultaneous and continuous evaluation of the three anatomical components of joint rotations (flexion/extension, collateromotion movements and axial rotations);

- to detail the method and algorithms in order to make them usable by every biologist or veterinarian;

- to assess its accuracy and particularly its capacity to detect the discrete modifications associated with uneven foot bearing.

\section{MATERIALS AND METHODS}

\subsection{Computational procedure}

\subsubsection{Horse limbs}

Four isolated left forelimbs were collected from horses who were euthanised for medical considerations. Radiographs of the digital joints were taken in order to ensure that they were not affected by osteo-articular lesions. The humeri were cut above the elbow joints, just at the proximal borders of the humeral insertion of the carpal extensor muscles. The insertions of the digital flexor muscles were preserved.

\subsubsection{Definition of local coordinate systems: trihedron design and fixation}

One trihedron per bony segment materialised the three axes of a coordinate system. The central parts of each trihedron were made of cubes with $14 \mathrm{~mm}$ sides. Three adjacent sides were drilled $5 \mathrm{~mm}$ deep in their centres and threaded to receive $2 \mathrm{~mm}$ stems. Four $4 \mathrm{~mm}$ spherical markers covered with scotchlite (Scotchlite 7610 - 3M, 
Cergy Pontoise, France) were screwed on these axes; two were on the $\mathrm{Z}$-axis $\left(\mathrm{P}_{3}\right.$ and $\left.\mathrm{P}_{4}\right)$ and the other two were placed on each $\mathrm{X}$-axis $\left(\mathrm{P}_{1}\right)$ and $\mathrm{Y}$-axis $\left(\mathrm{P}_{2}\right)$ (Fig. 1).

The origin of the coordinate system, called $\mathrm{O}$, was the intersection of the three axes; it was defined by $\overrightarrow{\mathrm{OP}}_{3}=\lambda \overrightarrow{\mathrm{P}_{4} \mathrm{P}_{3}}, \lambda$ being determined by the construction of the trihedron.

The metacarpal bone and the three phalanxes were drilled and a fourth axis linked each trihedron to the corresponding bone. The trihedrons were oriented in order to make the Z-axis coincide with the long axis of the bone, the Y-axis with the lateromedial direction and the $\mathrm{X}$-axis with the dorsopalmar axis. Because it was difficult to obtain an effective correspondence of the trihedron axes and bone directions, the measurements were based on this pre-set position of the trihedrons.

\subsubsection{Recording procedure}

The kinematics were performed using a method similar to the one developed for previous in vivo studies [20]. Three $8 \mathrm{~mm}$ video
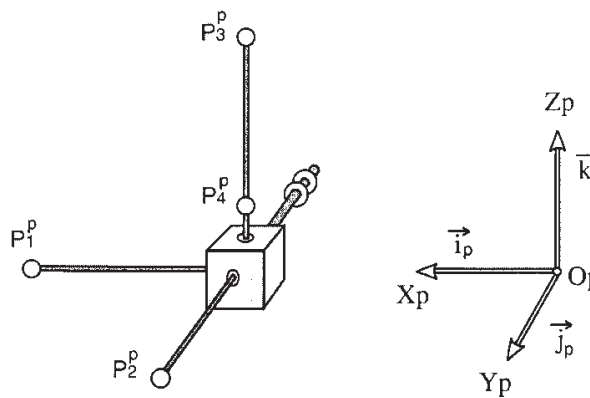

Figure 1. Geometric design of a trihedron and its related coordinate system. The indice $\mathrm{p}$ refers to a trihedron fixed to the proximal segment of a joint. The indice $d$ would refer to a trihedron fixed to the distal segment of a joint. cameras (Sony FX 700 - Sony, Japan) were placed on the left side of a press (MTS 10/MH - Adamel Lhomargy, France). Two of them were mounted on video tripods. They were focused on the central part of the press. The angle between their axes was about $60^{\circ}$. The third camera was raised 2.5 $\mathrm{m}$ high in order to record a proximodistallateromedial view of the limb. Two wedges $\left(6^{\circ}\right.$ and $\left.12^{\circ}\right)$ were used to raise the hoof.

For each test, a preliminary compressive load of $500 \mathrm{~N}$ was applied. From this initial position, the load was increased up to $6000 \mathrm{~N}$ by a regular displacement of the piston of the press $\left(500 \mathrm{~mm} \cdot \mathrm{min}^{-1}\right)$. The tests were recorded by the three video cameras at $25 \mathrm{~Hz}$. The cameras were synchronised by bulb lighting.

The first nine tests were devoted to heels elevation (three neutral tests, three with $6^{\circ}$ heels elevation, three with $12^{\circ}$ heels elevation, performed randomly in a latin square design). In the same manner, the nine next ones consisted in toe elevation and the nine other ones in lateral and medial side elevations.

After the test session, the space was calibrated using a geometric structure with markers of known coordinates. Thirty-six control points were evenly distributed in the whole control region [15]. They allowed spatial reconstruction on a field of view of $552 \mathrm{~mm}$ diagonal length.

\subsubsection{Three-dimensional transformation}

The films were analysed using the Equine Kinematic Analysis System (EKAS) developed for in vivo studies [39, 40]. The bidimensional coordinates of the markers of the trihedrons were measured on each film. The reconstruction of their three-dimensional coordinates was performed by the Direct Linear Transformation [1] which allows this determination as markers are moving in the calibrated space. 


\subsection{Modelling of the joint movement by JCS}

\subsubsection{Principle of the modelling}

Each trihedron defined a local coordinate system fixed to a bone, $R_{p}$ and $R_{d}$ being respectively the local coordinate systems associated to the proximal and distal segments of a joint. The rotation of an object is equivalent to the rotation of the coordinate system attached to it [44]. Kinematics provide a way to express $R_{p}$ and $R_{d}$ in $R_{0}$, and thus $R_{d}$ can be defined relative to $R_{p}$. This relative orientation of one body segment with respect to the other can also be expressed in terms of three successive rotations [19, 28] using the JCS [30]. This involves a specific sequence of cardanic angles in which the proximal segment was considered as the reference and the distal one moved relative to it. This sequence defines a specific system of axes presented in Figure 2. In this configuration, the distal local coordinate system is first assumed to be coincident with the proximal coordinate system [30]. Then, the distal segment rotates successively around three axes to its final orientation:

- the first movement is a rotation of an angle $\theta_{1}$ around the common $\mathrm{Y}$ axis $\left(\mathrm{Y}_{\mathrm{d}}=\mathrm{Y}_{\mathrm{p}}\right)$; it corresponds to the flexion/extension of the joint;

- then the distal segment rotates with an angle $\theta_{2}$ around the rotated $X^{\prime}$, called the floating axis [30], which is at each time orthogonal with the two extreme axes; it simulates the collateromotion of the joint;

- the final rotation is of an angle $\theta_{3}$ around the twice-rotated axis Z' (corresponding to $Z_{d}$ in its final position); it corresponds to the axial rotation of the joint.

\subsubsection{Angles calculation}

\subsubsection{Rotation matrix}

The flexion/extension movement is defined by a single rotation through angle $\theta_{1}$

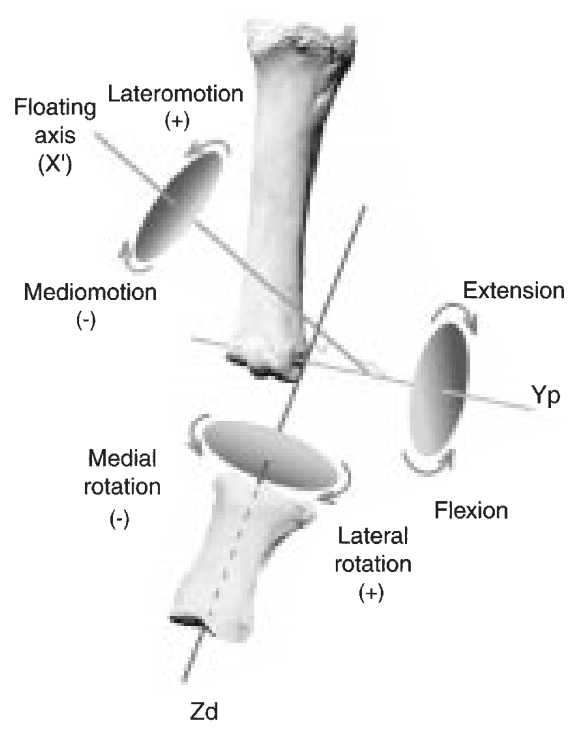

Figure 2. Definition of the Joint Coordinate System (example of the left metacarpophalangeal joint).

in the right-handed sense about the positive $\mathrm{Y}$-axis. It is represented by the elementary matrix $\mathrm{M}_{\mathrm{F}}$

$$
\mathrm{M}_{\mathrm{F}}=\left[\begin{array}{ccc}
\mathrm{C} 1 & 0 & -\mathrm{S} 1 \\
0 & 1 & 0 \\
\mathrm{~S} 1 & 0 & \mathrm{C} 1
\end{array}\right]
$$

where $\mathrm{C} 1$ refers to the cosine of angle $\theta 1$ and $S 1$ refers to the sine of angle $\theta_{1}$.

The collateromotion movement is defined by a single rotation through angle $\theta_{2}$ about the positive $\mathrm{X}$-axis. It is represented by the elementary matrix $\mathrm{M}_{\mathrm{C}}$

$$
\mathbf{M}_{\mathrm{C}}=\left[\begin{array}{ccc}
1 & 0 & 0 \\
0 & \mathrm{C} 2 & \mathrm{~S} 2 \\
0 & -\mathrm{S} 2 & \mathrm{C} 2
\end{array}\right] .
$$

The axial rotation is defined by a single rotation through angle $\theta_{3}$ about the positive 
$\mathrm{Z}$-axis. It is represented by the elementary matrix $\mathrm{M}_{\mathrm{R}}$

$$
M_{R}=\left[\begin{array}{ccc}
C 3 & S 3 & 0 \\
-S 3 & C 3 & 0 \\
0 & 0 & 1
\end{array}\right]
$$

The matrix $\mathrm{M}_{\mathrm{FCR}}$ for the composite rotations about body-fixed axes is [28, 44]:

$$
\mathrm{M}_{\mathrm{FCR}}=\mathrm{M}_{\mathrm{F}} \cdot \mathrm{M}_{\mathrm{C}} \cdot \mathrm{M}_{\mathrm{R}}
$$

thus

$$
\mathrm{M}_{\mathrm{FCR}}=\left[\begin{array}{ccc}
\mathrm{C} 1 \mathrm{C} 3-\mathrm{S} 1 \mathrm{~S} 2 \mathrm{~S} 3 & \mathrm{C} 1 \mathrm{~S} 3+\mathrm{S} 1 \mathrm{~S} 2 \mathrm{C} 3 & -\mathrm{S} 1 \mathrm{C} 2 \\
-\mathrm{C} 2 \mathrm{~S} 3 & \mathrm{C} 2 \mathrm{C} 3 & \mathrm{~S} 2 \\
\mathrm{~S} 1 \mathrm{C} 3-\mathrm{C} 1 \mathrm{~S} 2 \mathrm{~S} 3 & \mathrm{~S} 1 \mathrm{~S} 3-\mathrm{C} 1 \mathrm{~S} 2 \mathrm{C} 3 & \mathrm{C} 1 \mathrm{C} 2
\end{array} \mid\right.
$$

where $\vec{V}_{d}=M_{F C R} \cdot \vec{V}_{p}\left(\vec{V}_{p}\right.$ is a vector in $R_{p}$; $\vec{V}_{d}$ is the same vector expressed in $R_{d}$ ).

\subsubsection{Transformation matrix}

$\mathrm{R}_{0}$ is the global coordinate system determined by the kinematics calibration. It is defined by $\left(\mathrm{O}_{0}, \overrightarrow{\mathrm{x}_{0}}, \overrightarrow{\mathrm{y}_{0}}, \overrightarrow{\mathrm{z}_{0}}\right) . \overrightarrow{\mathrm{x}_{0}}$ is on the $\mathrm{X}_{0^{-}}$ axis (palmaro-dorsal), $\overrightarrow{\mathrm{y}}_{0}$ on the $\mathrm{Y}_{0}$-axis (medio-lateral) and $\overrightarrow{\mathrm{z}}_{0}$ on the $\mathrm{Z}_{0}$-axis (distoproximal).

$\mathrm{R}_{\mathrm{p}}$ is the local coordinate system associated with the proximal segment. It is defined by $\left(\mathrm{O}_{\mathrm{p}}, \overrightarrow{\mathrm{i}_{\mathrm{p}}}, \overrightarrow{\mathrm{j}_{\mathrm{p}}}, \overrightarrow{\mathrm{k}_{\mathrm{p}}}\right)$. In the same way, $\mathrm{R}_{\mathrm{d}}$ is defined by $\left(\mathrm{O}_{\mathrm{d}}, \overrightarrow{\mathrm{i}_{\mathrm{d}}}, \overrightarrow{\mathrm{j}_{\mathrm{d}}}, \overrightarrow{\mathrm{k}_{\mathrm{d}}}\right)$ (Fig. 3).

The global matrix searched is $M_{d / p}$ so that $\vec{V}_{d}=M_{d / p} \cdot \vec{V}_{p}$ where $\vec{V}_{p}$ is a vector expressed in $R_{p}$ and $\vec{V}_{d}$ the same vector expressed in $R_{d}$.

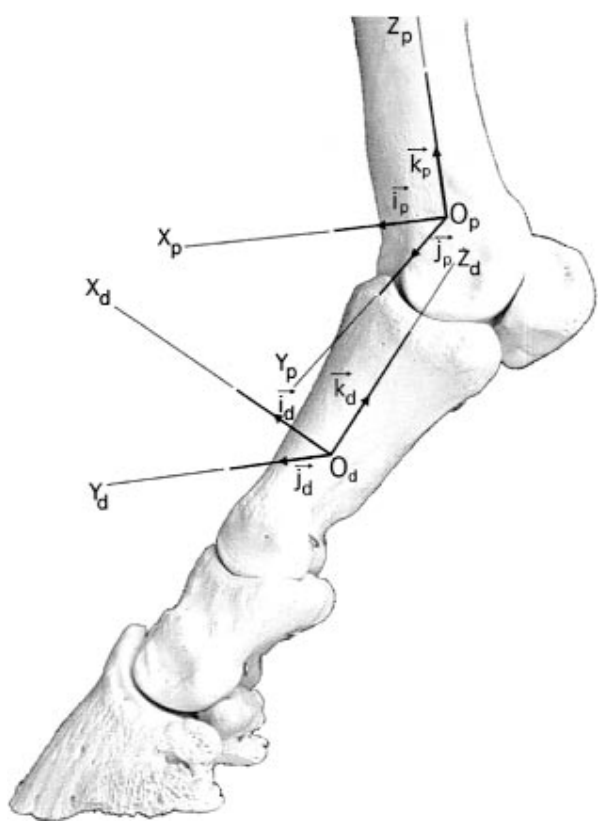

Figure 3. Local coordinate systems associated with the trihedrons (example of the metacarpophalangeal joint).

- Definition of a right-handed orthogonal local coordinate system

The four markers of a trihedron define three vectors associated to each axis.

$$
\begin{aligned}
& \overrightarrow{\mathrm{u}_{1}^{\mathrm{p}}}=\overrightarrow{\mathrm{P}_{0}^{\mathrm{p}} \mathrm{P}_{1}^{\mathrm{p}}}=\overrightarrow{\mathrm{P}_{0}^{\mathrm{p}} \mathrm{P}_{4}^{\mathrm{p}}}+\overrightarrow{\mathrm{P}_{4}^{\mathrm{p}} \mathrm{P}_{1}^{\mathrm{p}}}=\lambda \overrightarrow{\mathrm{P}_{4}^{\mathrm{p}} \mathrm{P}_{3}^{\mathrm{p}}}+\overrightarrow{\mathrm{P}_{4}^{\mathrm{p}} \mathrm{P}_{1}^{\mathrm{p}}} \\
& \overrightarrow{\mathrm{u}_{2}^{\mathrm{p}}}=\overrightarrow{\mathrm{P}_{0}^{\mathrm{p}} \mathrm{P}_{2}^{\mathrm{p}}}=\overrightarrow{\mathrm{P}_{0}^{\mathrm{p}} \mathrm{P}_{4}^{\mathrm{p}}}+\overrightarrow{\mathrm{P}_{4}^{\mathrm{p}} \mathrm{P}_{2}^{\mathrm{p}}}=\lambda \overrightarrow{\mathrm{P}_{4}^{\mathrm{p}} \mathrm{P}_{3}^{\mathrm{p}}}+\overrightarrow{\mathrm{P}_{4}^{\mathrm{p}} \mathrm{P}_{2}^{\mathrm{p}}} \\
& \overrightarrow{\mathrm{u}_{3}^{\mathrm{p}}}=\overrightarrow{\mathrm{P}_{0}^{\mathrm{p}} \mathrm{P}_{3}^{\mathrm{p}}}=\overrightarrow{\mathrm{P}_{0}^{\mathrm{p}} \mathrm{P}_{4}^{\mathrm{p}}}+\overrightarrow{\mathrm{P}_{4}^{\mathrm{p}} \mathrm{P}_{3}^{\mathrm{p}}}=(\lambda+1) \overrightarrow{\mathrm{P}_{4}^{\mathrm{p}} \mathrm{P}_{3}^{\mathrm{p}}}
\end{aligned}
$$

with $\overrightarrow{\mathrm{P}_{0}^{\mathrm{p}} \mathrm{P}_{4}^{\mathrm{p}}}=\lambda \overrightarrow{\mathrm{P}_{4}^{\mathrm{p}} \mathrm{P}_{3}^{\mathrm{p}}}$ and $\lambda$ known by the construction of the trihedron. 
The vectors $\overrightarrow{\mathrm{O}_{0} \mathrm{P}_{1}^{\mathrm{p}}}, \overrightarrow{\mathrm{O}_{0} \mathrm{P}_{2}^{\mathrm{p}}}, \overrightarrow{\mathrm{O}_{0} \mathrm{P}_{3}^{\mathrm{p}}}, \overrightarrow{\mathrm{O}_{0} \mathrm{P}_{4}^{\mathrm{p}}}$ are measured in $\mathrm{R}_{0}$ by kinematics

$$
\overrightarrow{\mathrm{O}_{0} \mathrm{P}_{\mathrm{n}}^{\mathrm{p}}}=\mathrm{x}_{\mathrm{n}}^{\mathrm{p}} \cdot \overrightarrow{x_{0}}+\mathrm{y}_{\mathrm{n}}^{\mathrm{p}} \cdot \overrightarrow{y_{0}}+\mathrm{z}_{\mathrm{n}}^{\mathrm{p}} \cdot \overrightarrow{z_{0}}
$$

where $n \in\{1,2,3,4\}$

$$
\begin{aligned}
\overrightarrow{\mathrm{P}_{4}^{\mathrm{p}} \mathrm{P}_{1}^{\mathrm{p}}} & =\overrightarrow{\mathrm{P}_{4}^{\mathrm{p}} \mathrm{O}_{0}}+\overrightarrow{\mathrm{O}_{0} \mathrm{P}_{1}^{\mathrm{p}}} \\
& =\left(\mathrm{x}_{1}^{\mathrm{p}}-\mathrm{x}_{4}^{\mathrm{p}}\right) \overrightarrow{\mathrm{x}_{0}}+\left(\mathrm{y}_{1}^{\mathrm{p}}-\mathrm{y}_{4}^{\mathrm{p}}\right) \overrightarrow{\mathrm{y}_{0}}+\left(\mathrm{z}_{1}^{\mathrm{p}}-\mathrm{z}_{4}^{\mathrm{p}}\right) \overrightarrow{\mathrm{z}_{0}} \\
\overrightarrow{\mathrm{P}_{4}^{\mathrm{p}} \mathrm{P}_{2}^{\mathrm{p}}} & =\overrightarrow{\mathrm{P}_{4}^{\mathrm{p}} \mathrm{O}_{0}}+\overrightarrow{\mathrm{O}_{0} \mathrm{P}_{2}^{\mathrm{p}}} \\
& =\left(\mathrm{x}_{2}^{\mathrm{p}}-\mathrm{x}_{4}^{\mathrm{p}}\right) \overrightarrow{\mathrm{x}_{0}}+\left(\mathrm{y}_{2}^{\mathrm{p}}-\mathrm{y}_{4}^{\mathrm{p}}\right) \overrightarrow{\mathrm{y}_{0}}+\left(\mathrm{z}_{2}^{\mathrm{p}}-\mathrm{z}_{4}^{\mathrm{p}}\right) \overrightarrow{\mathrm{z}_{0}} \\
\overrightarrow{\mathrm{P}_{4}^{\mathrm{p}} \mathrm{P}_{3}^{\mathrm{p}}} & =\overrightarrow{\mathrm{P}_{4}^{\mathrm{p}} \mathrm{O}_{0}}+\overrightarrow{\mathrm{O}_{0} \mathrm{P}_{4}^{\mathrm{p}}} \\
& =\left(\mathrm{x}_{3}^{\mathrm{p}}-\mathrm{x}_{4}^{\mathrm{p}}\right) \overrightarrow{\mathrm{x}_{0}}+\left(\mathrm{y}_{3}^{\mathrm{p}}-\mathrm{y}_{4}^{\mathrm{p}}\right) \overrightarrow{\mathrm{y}_{0}}+\left(\mathrm{z}_{3}^{\mathrm{p}}-\mathrm{z}_{4}^{\mathrm{p}}\right) \overrightarrow{\mathrm{z}_{0}} .
\end{aligned}
$$

Thus

$$
\begin{aligned}
\overrightarrow{\mathrm{u}_{1}^{\mathrm{p}}}= & {\left[\lambda\left(\mathrm{x}_{3}^{\mathrm{p}}-\mathrm{x}_{4}^{\mathrm{p}}\right)+\left(\mathrm{x}_{1}^{\mathrm{p}}-\mathrm{x}_{4}^{\mathrm{p}}\right)\right] \overrightarrow{\mathrm{x}_{0}} } \\
& +\left[\lambda\left(\mathrm{y}_{3}^{\mathrm{p}}-\mathrm{y}_{4}^{\mathrm{p}}\right)+\left(\mathrm{y}_{1}^{\mathrm{p}}-\mathrm{y}_{4}^{\mathrm{p}}\right)\right] \overrightarrow{\mathrm{y}}_{0} \\
& +\left[\lambda\left(\mathrm{z}_{3}^{\mathrm{p}}-\mathrm{z}_{4}^{\mathrm{p}}\right)+\left(\mathrm{z}_{1}^{\mathrm{p}}-\mathrm{z}_{4}^{\mathrm{p}}\right)\right] \overrightarrow{\mathrm{z}_{0}} \\
\overrightarrow{\mathrm{u}_{1}^{\mathrm{p}}}= & \mathrm{X}_{1}^{\mathrm{p}} \overrightarrow{\mathrm{x}_{0}}+\mathrm{Y}_{1}^{\mathrm{p} \mathrm{y}_{0}}+\mathrm{Z}_{1}^{\mathrm{p}} \overrightarrow{\mathrm{z}_{0}} \\
\overrightarrow{\mathrm{u}_{2}^{\mathrm{p}}=}= & {\left[\lambda\left(\mathrm{x}_{3}^{\mathrm{p}}-\mathrm{x}_{4}^{\mathrm{p}}\right)+\left(\mathrm{x}_{2}^{\mathrm{p}}-\mathrm{x}_{4}^{\mathrm{p}}\right)\right] \overrightarrow{\mathrm{x}_{0}} } \\
& +\left[\lambda\left(\mathrm{y}_{3}^{\mathrm{p}}-\mathrm{y}_{4}^{\mathrm{p}}\right)+\left(\mathrm{y}_{2}^{\mathrm{p}}-\mathrm{y}_{4}^{\mathrm{p}}\right)\right] \overrightarrow{\mathrm{y}_{0}} \\
& +\left[\lambda\left(\mathrm{z}_{3}^{\mathrm{p}}-\mathrm{z}_{4}^{\mathrm{p}}\right)+\left(\mathrm{z}_{2}^{\mathrm{p}}-\mathrm{z}_{4}^{\mathrm{p}}\right)\right] \overrightarrow{\mathrm{z}_{0}} \\
\overrightarrow{\mathrm{u}_{2}^{\mathrm{p}}=} & \mathrm{X}_{2}^{\mathrm{p}} \overrightarrow{\mathrm{x}_{0}}+\mathrm{Y}_{2}^{\mathrm{p}} \overrightarrow{\mathrm{y}_{0}}+\mathrm{Z}_{2}^{\mathrm{p}} \overrightarrow{\mathrm{z}_{0}} \\
\overrightarrow{\mathrm{u}_{3}^{\mathrm{p}}}= & {\left[(\lambda+1)\left(\mathrm{x}_{3}^{\mathrm{p}}-\mathrm{x}_{4}^{\mathrm{p}}\right)\right] \overrightarrow{\mathrm{x}_{0}} } \\
& +\left[(\lambda+1)\left(\mathrm{y}_{3}^{\mathrm{p}}-\mathrm{y}_{4}^{\mathrm{p}}\right)\right] \overrightarrow{\mathrm{y}_{0}} \\
& +\left[(\lambda+1)\left(\mathrm{z}_{3}^{\mathrm{p}}-\mathrm{z}_{4}^{\mathrm{p}}\right)\right] \overrightarrow{\mathrm{z}_{0}} \\
\overrightarrow{\mathrm{u}_{3}^{\mathrm{p}}}= & X_{3}^{\mathrm{p}} \overrightarrow{\mathrm{x}_{0}}+\mathrm{Y}_{3}^{\mathrm{p}} \overrightarrow{\mathrm{y}_{0}}+\mathrm{Z}_{3}^{\mathrm{p}} \overrightarrow{\mathrm{z}_{0}} .
\end{aligned}
$$

$\overrightarrow{\mathrm{i}_{\mathrm{p}}}, \overrightarrow{\mathrm{j}_{\mathrm{p}}}, \overrightarrow{\mathrm{k}_{\mathrm{p}}}$ can be expressed as:

$$
\begin{aligned}
& \overrightarrow{\mathrm{i}_{\mathrm{p}}}=\frac{\overrightarrow{\mathrm{u}_{1}^{\mathrm{p}}}}{\| \overrightarrow{\mathrm{u}_{1}^{\mathrm{p}} \|}}=\frac{\mathrm{X}_{1}^{\mathrm{p}}}{\mathrm{N}_{1}^{\mathrm{p}}} \overrightarrow{\mathrm{x}_{0}}+\frac{\mathrm{Y}_{1}^{\mathrm{p}}}{\mathrm{N}_{1}^{\mathrm{p}}} \overrightarrow{\mathrm{y}_{0}}+\frac{\mathrm{Z}_{1}^{\mathrm{p}}}{\mathrm{N}_{1}^{\mathrm{p}}} \overrightarrow{\mathrm{z}_{0}} \\
& \overrightarrow{\mathrm{j}_{\mathrm{p}}}=\frac{\overrightarrow{\mathrm{u}_{2}^{\mathrm{p}}}}{\| \overrightarrow{\mathrm{u}_{2}^{\mathrm{p}} \|}}=\frac{\mathrm{X}_{2}^{\mathrm{p}}}{\mathrm{N}_{2}^{\mathrm{p}}} \overrightarrow{\mathrm{x}_{0}}+\frac{\mathrm{Y}_{2}^{\mathrm{p}}}{\mathrm{N}_{2}^{\mathrm{p}}} \overrightarrow{\mathrm{y}_{0}}+\frac{\mathrm{Z}_{2}^{\mathrm{p}}}{\mathrm{N}_{2}^{\mathrm{p}}} \overrightarrow{\mathrm{z}_{0}} \\
& \overrightarrow{\mathrm{k}_{\mathrm{p}}}=\frac{\overrightarrow{\mathrm{u}_{3}^{\mathrm{p}}}}{\| \overrightarrow{\mathrm{u}_{3}^{\mathrm{p}} \|}}=\frac{\mathrm{X}_{3}^{\mathrm{p}}}{\mathrm{N}_{3}^{\mathrm{p}}} \overrightarrow{\mathrm{x}_{0}}+\frac{\mathrm{Y}_{3}^{\mathrm{p}}}{\mathrm{N}_{3}^{\mathrm{p}}} \overrightarrow{\mathrm{y}_{0}}+\frac{\mathrm{Z}_{3}^{\mathrm{p}}}{\mathrm{N}_{3}^{\mathrm{p}}} \overrightarrow{\mathrm{z}_{0}}
\end{aligned}
$$

with $\mathrm{N}_{\mathrm{n}}^{\mathrm{p}}=\sqrt{\mathrm{X}_{\mathrm{n}}^{\mathrm{p}^{2}}+\mathrm{Y}_{\mathrm{n}}^{\mathrm{p}^{2}}+Z_{\mathrm{n}}^{\mathrm{p}^{2}}}$ where $\mathrm{n} \in$ $\{1,2,3\}$.

- Calculation of the transformation matrix

$\mathrm{M}_{\mathrm{p} / 0}$ and $\mathrm{M}_{\mathrm{d} / 0}$ are the matrix expressing $\mathrm{R}_{\mathrm{p}}$ and $\mathrm{R}_{\mathrm{d}}$ in $\mathrm{R}_{\mathrm{O}}$

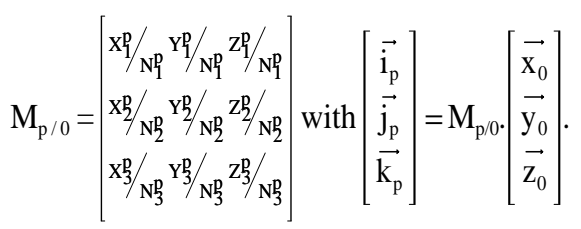

In the same way,

$$
\mathrm{M}_{\mathrm{d} / 0}=\left[\begin{array}{l}
\mathrm{x}_{1}^{\mathrm{d}} / \mathrm{N}_{1}^{\mathrm{d}} \mathrm{Y}_{1}^{\mathrm{d}} / \mathrm{N}_{1}^{\mathrm{d}} \mathrm{Z}_{1}^{\mathrm{d}} / \mathrm{N}_{1}^{\mathrm{d}} \\
\mathrm{x}_{2}^{\mathrm{d}} / \mathrm{N}_{2}^{\mathrm{d}} \mathrm{Y}_{2}^{\mathrm{d}} / \mathrm{Nd}_{2}^{\mathrm{d}} \mathrm{z}_{2}^{\mathrm{d}} / \mathrm{N}_{2}^{\mathrm{d}} \\
\mathrm{x}_{3}^{\mathrm{d}} / \mathrm{N}_{3}^{\mathrm{d}} \mathrm{Y}_{3}^{\mathrm{d}} / \mathrm{N}_{3}^{\mathrm{d}} \mathrm{Z}_{3}^{\mathrm{d}} / \mathrm{N}_{3}^{\mathrm{d}}
\end{array}\right] \text { with }\left[\begin{array}{l}
\overrightarrow{\overrightarrow{\mathrm{j}}_{\mathrm{d}}} \\
\overrightarrow{\overrightarrow{\mathrm{j}}_{\mathrm{d}}} \\
\overrightarrow{\mathrm{k}_{\mathrm{d}}}
\end{array}\right]=\mathrm{M}_{\mathrm{d} / 0 \cdot}\left[\begin{array}{l}
\overrightarrow{\mathrm{x}_{0}} \\
\overrightarrow{\mathrm{y}_{0}} \\
\overrightarrow{\mathrm{z}_{0}}
\end{array}\right] \text {. }
$$

The global matrix can be expressed as $\mathrm{M}_{\mathrm{d} / \mathrm{p}}=\mathrm{M}_{\mathrm{d} / 0} \cdot \mathrm{M}_{0 / \mathrm{p}}=\mathrm{M}_{\mathrm{d} / 0} \cdot \mathrm{M}_{\mathrm{p} / 0}^{\mathrm{T}}$

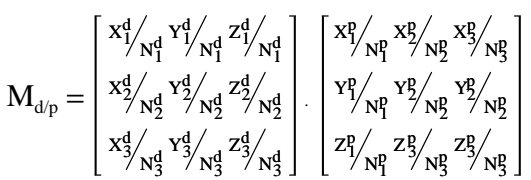

$$
\begin{aligned}
& =\left[\begin{array}{lll}
r_{11} & r_{12} & r_{13} \\
r_{21} & r_{22} & r_{23} \\
r_{31} & r_{32} & r_{33}
\end{array}\right] \\
& r_{n m}=\frac{X_{n}^{d}}{N_{n}^{d}} \cdot \frac{X_{m}^{p}}{N_{m}^{p}}+\frac{Y_{n}^{d}}{N_{n}^{d}} \cdot \frac{Y_{m}^{p}}{N_{m}^{p}}+\frac{Z_{n}^{d}}{N_{n}^{d}} \cdot \frac{Z_{m}^{p}}{N_{m}^{p}}
\end{aligned}
$$

with $\mathrm{n}$ and $\mathrm{m} \in\{1,2,3\}$. 


$$
\begin{aligned}
& \text { 2.2.2.3. Equality of rotation and } \\
& \text { transformation matrix; } \\
& \text { calculation of the } \\
& \text { elementary angles } \\
& \mathrm{M}_{\mathrm{FCR}}=\left[\begin{array}{ccc}
\mathrm{C} 1 \mathrm{C} 3-\mathrm{S} 1 \mathrm{~S} 2 \mathrm{~S} 3 & \mathrm{C} 1 \mathrm{~S} 3+\mathrm{S} 1 \mathrm{~S} 2 \mathrm{C} 3 & -\mathrm{S} 1 \mathrm{C} 2 \\
-\mathrm{C} 2 \mathrm{~S} 3 & \mathrm{C} 2 \mathrm{C} 3 & \mathrm{~S} 2 \\
\mathrm{~S} 1 \mathrm{C} 3-\mathrm{C} 1 \mathrm{~S} 2 \mathrm{~S} 3 & \mathrm{~S} 1 \mathrm{~S} 3-\mathrm{C} 1 \mathrm{~S} 2 \mathrm{C} 3 & \mathrm{ClC} 2
\end{array}\right] \\
& =\mathrm{M}_{\mathrm{d} / \mathrm{p}}=\left[\begin{array}{lll}
\mathrm{r}_{11} \mathrm{r}_{12} \mathrm{r}_{13} \\
\mathrm{r}_{21} \mathrm{r}_{22} \mathrm{r}_{23} \\
\mathrm{r}_{31} \mathrm{r}_{32} \mathrm{r}_{33}
\end{array}\right] .
\end{aligned}
$$

Thus $\theta_{1}=-\operatorname{atan} \frac{r_{1}}{r_{3:}}, \theta_{2}=\operatorname{asin} r_{23}, \theta_{3}=-\operatorname{atan} \frac{r_{2}}{r_{2}}$.

\subsubsection{Computation of $\theta_{1}, \theta_{2}$ and $\theta_{3}$ - statistical analysis}

The three-dimensional coordinates of the markers were exported in Microsoft Excel (Microsoft Software - Microsoft France, France). Angles $\theta_{1}, \theta_{2}$ and $\theta_{3}$ were calculated via the given formula. The angle values at the beginning and the end of each test were calculated. The results obtained were compared using the ANOVA procedure (SAS - SAS Institute, North Carolina, USA). The level of $P<0.05$ was chosen for statistical significance.

\section{RESULTS}

The absolute data were different from one horse to another but the relative data, expressed as the difference between the wedge tests and the neutral ones, were very similar. The four limbs demonstrated similar patterns after data were normalised to the neutral one.

\subsection{Flexion/extension measurements}

During the neutral tests (flat foot, without any wedge), the metacarpophalangeal joint underwent an extension, the proximal interphalangeal joint a discreet flexion and the distal interphalangeal joint a more pronounced flexion.

For all horses, raising the heels had little influence on the metacarpophalangeal joint but modified the flexion/extension patterns of both interphalangeal joints. The flexion of the proximal interphalangeal joint was significantly increased by the wedges at the end of the test (Fig. 4). The distal interphalangeal joint was more flexed. The decrease of its palmar angle was equal to the wedge size.

Inversely, toe elevation provoked an increase of extension of both interphalangeal joints compared to the neutral test, and also had little influence on the metacarpophalangeal joint.

\subsection{Collateromotion measurements}

For all horses and joints, the elevation of the lateral side of the hoof provoked a lateromotion of the digital joints (Fig. 5). The elevation of the medial side induced the opposite phenomenon (mediomotion).

\subsection{Lateral/medial rotation measurements}

For all horses, the three digital joints underwent a rotation opposite of the side of elevation. As an example, Figure 6 shows the influence of the elevation of lateral and medial sides of the hoof on the proximal interphalangeal joint. A medial sided elevation induced a lateral rotation of the proximal phalanx. Inversely, a lateral sided elevation induced a medial rotation. 


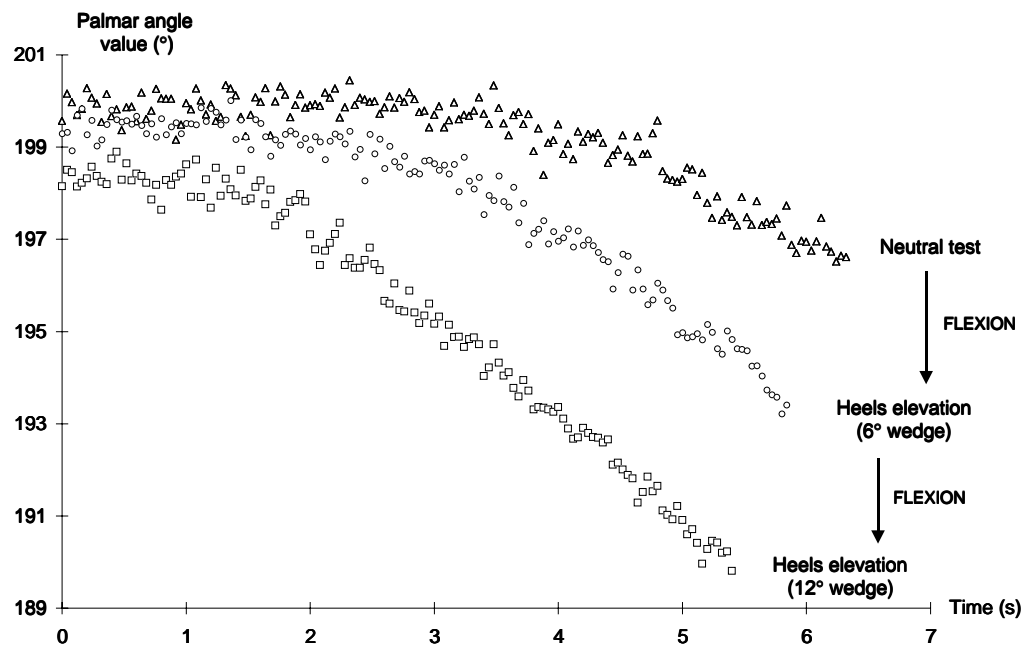

Figure 4. Influence of heels raising on the flexion of the proximal interphalangeal joint. Raising the heels increases the proximal interphalangeal flexion (example of horse 1).

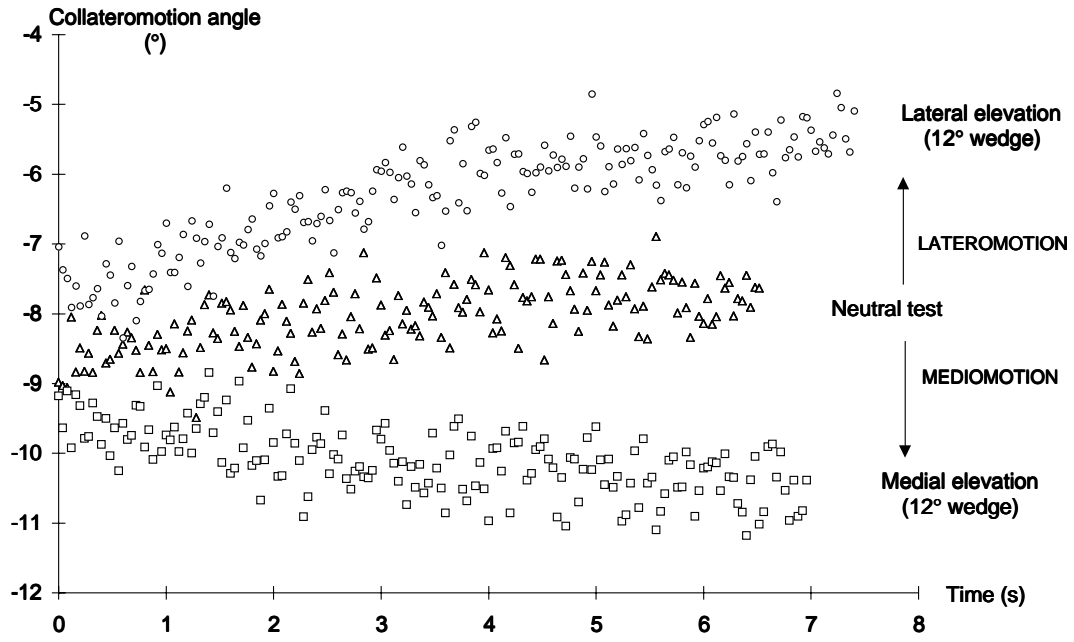

Figure 5. Influence of latero-medial hoof elevation on the collateromotion of the metacarpophalangeal joint. Medial side elevation (with $12^{\circ}$ wedge) induces a mediomotion and lateral side elevation a lateromotion (example of horse 4).

\section{DISCUSSION}

Modelling of the digital joints of the horse - The joint is the interface at which relative motion is allowed between two rigid bodies [34]. The anatomical joints are com- plex and have typically six degrees of freedom (DOF): three in rotation and three in translation. However, in many cases a full six DOF description and measurement is not required or even helpful, and many researchers have measured and described 


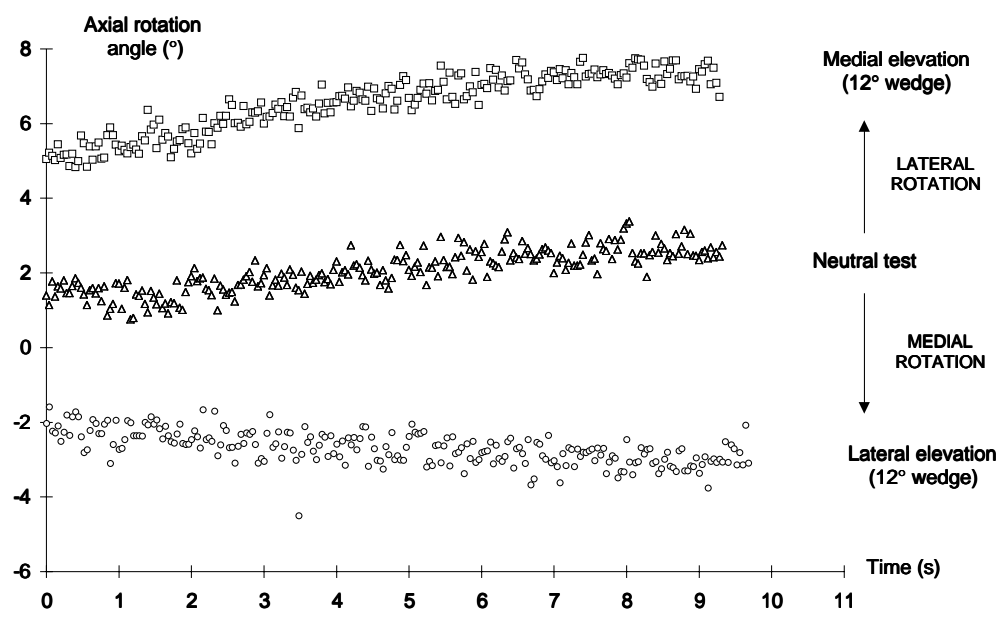

Figure 6. Influence of latero-medial hoof elevation on the axial rotation of the proximal interphalangeal joint. Medial side elevation (with $12^{\circ}$ wedge) induces lateral rotation and lateral side elevation, medial rotation (example of horse 1 ).

joint motion with less than six DOF for valid reasons [9]. Moreover the description of joint motion must be suitable for the application and use of the available data. Because such a modelling had never been performed for the joints of the horse, we had to make the choice of a model on the basis of the functional anatomy of the digital joints of the horse.

Joint motions involved in daily activities are defined by the articular bone surfaces and the soft tissues around them. The metacarpophalangeal joint is a typical condylar joint with an intermediate relief. It involves mainly flexion/extension movements in the sagittal plane and limited associated motions. The two interphalangeal joints have similar condylar surfaces allowing mainly flexion/extension movements in the sagittal plane. The lower congruence of these joints permits rotational movements that can be detected by the human eye as horses are running a curve, especially for the distal interphalangeal joint. These condyles prevent sliding but low amplitude translational motions still exist in the equine digital complex [23].
The study was limited to rotation DOF. The main reason for this choice was that the computation of translational motion is difficult. First, translations are difficult to define precisely by the kinematics [11], as they are generally very small and prone to be hidden by experimental artefacts and errors [28]. Second, rotations are independent of the choice of the base point, but the magnitude of the translation vector, and hence its components, depends upon where the reference points are located in each bone [30]. This implies that the external coordinate systems cannot be directly used to compute the translations but should be re-located at a specific point of the bones. This operation is difficult and poorly accurate since it implies a radiographic step. Third, no commonly accepted convention exists that defines functionally significant translational directions when the joint is in an arbitrary configuration $[2,30]$. Furthermore, the rotations are independent of the translations [44] and the choice to study only rotations will not have any incidence on the quality of the results.

The equine digit was assumed to be an opened chain of three universal motors [14]. 
The model chosen was the three DOF spherical joint [9]. The three DOF were affected to the three anatomical rotations.

The geometric model was chosen according to the recommendations of the International society of Biomechanics (ISB) [55]. They involve a joint coordinate system in which a rotation occurs about one axis of the local reference frame of the proximal segment, a rotation about one axis of the local reference frame of the distal segment and a rotation about the floating axis, perpendicular to the two other ones $[14,29,30$, 55]. This presents the great advantage of preserving an important linkage with clinical medicine where the use of independent paired rotations is common usage [55].

The two segment-fixed axes had to be chosen carefully because they determine the sequence of successive rotations. This point was very important since the results are dependent of the sequence $[4,18,30,44$, 54] except if the three angles are small; this is not the case in the equine digital joints where the flexion pattern is important compared to the associated movements of collateromotion and axial rotation. Therefore, the six possible combinations of three rotations provide theoretically six series of different results: the sequence must be exactly specified to give a sense to the results [44]. Moreover the three angles calculated in a sequence are dependent on each other: an angle value is meaningful since it is associated to the two other ones [30].

Considering that the joint underwent a flexion [F], a collateromotion [C] and an axial rotation $[R]$, six combinations of rotations were possible. The six sequences were tested on a lateral wedge test. The [RFC] and [CFR] sequences gave atypical results which confirmed the observations of Blankevoort et al [8] who demonstrated that the effect of the sequence is relatively small only if the large amplitude motion $[\mathrm{F}]$ is not at the centre of the sequence. These sequences were eliminated. The [FCR] and [FRC] sequences provided the same results; the $[\mathrm{RCF}]$ and $[\mathrm{CRF}]$ ones did the same. Furthermore, the curves obtained with these four sequences had similar shapes in time as observed by other authors in the human knee [28, 54].

We arbitrarily decided to conserve the convention of Chao [14] and Grood and Suntay [30], which is generally used in human biomechanics $[46,55]$, for the horse. This joint coordinate system corresponds to the following convention of cardanic angles: the coordinate systems of two adjacent bones are first assumed coincident, then the distal coordinate segment moved relative to the proximal one, considered as the reference, following a sequence of three successive rotations. The first was through the Y-axis of the segment (flexion/extension), then through the rotated $X^{\prime}$-axis (collateromotion) and finally through the twice-rotated Z' '-axis (axial rotation). Only two axes have a physical representation, the first axis which is made visible by $Y_{p}$ and the final one which is $Z_{d}$. The intermediate axis, called floating axis, is perpendicular to the other two ones [18, 30].

This notion of sequence presents the advantage of clarifying the relations between the three elementary movements. Considering a perfect mechanical ball-and-socket joint, it is easy to define a system of orthogonal axes and, in this linkage, each movement is independent of the other ones. But articular surfaces are not so simple and the three movements are always associated. Furthermore, the soft tissues surrounding the joint decide of the type of pattern [7].

Use of bony-implanted trihedrons - The great majority of in vivo studies involves a set of reflective markers sticking on the skin. The sliding of the skin over bony landmarks may however change the results [51]. The contraction of the muscles and the tension of ligaments also generate external deformations [12]. The influence of skin movements on the accuracy of determination of these small amplitude movements was evaluated on the human knee [43]. Skin mounted 
markers were only able to give a good representation of skeletal motion for flexion/extension. The agreement between skin and bone markers for rotation and adduction/abduction movements was poor. Such a study was not realised on moving horses but the large amplitude of skin sliding over the proximal parts of the equine limbs [49] may produce large artefacts which counteract the rigid body theory on which angle calculations are based. The physical solution to address this problem is to mount three (or more) markers on a rigid object which is securely strapped to the body segment [16]. Thus we used trihedrons drilled to the bones, allowing us to apply the rigid body theory unambiguously in order to calculate segmental kinematics from the measured marker coordinates.

The orientation of a solid in space is known if a minimal number of three noncollinear markers are used. We used four markers in a first attempt since they give a good representation of the local coordinate frame. Two unit vectors are physically defined using three of our markers and the third one can be computed from the vectorial product of the two other ones. Its coordinates can be easily integrated to the formula.

Orientation of the trihedrons - This method also implies strongly fixing the trihedrons to the bones and paying special attention to the positioning of their axes. The measurement of rotations is dependent of the local coordinate system orientation but independent of the choice of the base point [44]. The trihedron can be fixed everywhere on the bone but its axes should be oriented toward the supposed anatomical axes of the bony segment. Small errors in the orientation of the axes induce an imprecision on absolute angle data [32]. However relative results such as the comparison between different test conditions or amplitude measurements are still available. In that way, the neutral test provides the reference data to which the other tests are compared. This is confirmed experimentally by the intra- (IAV) and inter-individual (IEV) variability of the absolute and relative data (difference between the value of a wedged test and a neutral one). The IAV of a parameter for the population is the mean of the standard deviation of this parameter for the four horses. The IEV of a parameter for the population is the standard deviation of the means of this parameter for the four horses [21]. Considering the absolute data, their IEV are high compared to their IAV: parameter measurements are repeatable for each horse but horses are different. However the relative data (difference between wedge value and neutral test) have IEV that are similar to the IAV: the discreet error of orientation of the trihedrons does not allow the accurate determination of absolute data but the analysis of the influence of hoof elevation compared to a flat-footed position is valuable.

Reliability to other experiments - The results obtained with the varied experimental conditions are correlated with previously reported semi-quantitative results. Concerning flexion and extension, in vivo studies involved radiographic measurements of the metacarpophalangeal angulation on horses standing square with different angulation wedges placed under their heels [10]. It was demonstrated that raising heels had little influence on the metacarpophalangeal joints. The increase of flexion of both interphalangeal joints associated with heels raising was also demonstrated in vivo by radiographic evaluations [10, 12, 25]. The modelling and experimental design detailed here provided objective data which are consistent with previously published results. Moreover it allowed continuous measurements during loading.

Concerning movements occurring in the other planes, radiography and coloured articular surfaces demonstrated that the elevation of one side of the hoof is associated with rotation of the digital joints on the side opposite of the compression. In the same way, the phenomenon of collateromotion of the joint on the side of the elevation has 
also been previously documented [23]. Before this study, no quantitative measurements were available for these movements in the horse. The method presented here provides an efficient way to quantify them.

Precision of the method - The precision of the method was evaluated using the fact that trihedrons are non-deformable structures [44], thus the distances and angles between the markers of each trihedron remain constant. Four distances and four angles between markers were measured for each trihedron after $3 \mathrm{D}$ reconstruction. This provided 16 distances and 16 angles at each frame. The standard deviations of distances and angles were calculated for the first neutral test of each limb. The maximal mean standard deviation was $0.3^{\circ}$ for angles and $0.2 \mathrm{~mm}$ for distances. It appears difficult to further evaluate the precision because it is so high, that to make a comparison of standard values with computed values meaningful, would necessitate advanced apparatuses able to detect very small rotations. Considering the diagonal length of the field of view, the performance index of the system was 2560 , which is superior to the in vivo conditions [20].

The direct observation of the results gives a way to assess the good performance of the method. As an example, raising the heels with a $6^{\circ}$ wedge induced a discrete increase of flexion of the proximal interphalangeal joint at the beginning of the test. The mean difference between this condition and the neutral one was $0.7^{\circ}$, was repeatable and had statistical significance. This low rate demonstrates the ability of the method to identify discrete angular modifications such as those generated by hoof elevations.

This kinematic technique completes the radiographic method in which measurements are difficult: the incidence of the radiographs, the conic distortion of large objects, and the definition of a coherent coordinate system limit its accuracy. Furthermore, axial rotation is difficult to evaluate. In the optimal case of the human vertebra, their axial rotation associated with scoliosis can be evaluated by the asymmetry of the shadows of the vertebral pedicles. But the precision remains poor (about $5^{\circ}$ ) [45].

Application to living animals - Up to this day, this experimentation was conducted on separated horse limbs. The tendons and their accessory ligaments are viscoelastic cords. They lengthen during limb loading and shorten as the charge is removed. This ability of the equine limb to go back to its original configuration, without any muscular action, allows the repetition of in vitro tests. However, the experimental conditions differ from those associated with living horses. As an example, the low speed displacement of the piston increases the duration of limb loading. These in vitro data are valuable to understand the functional anatomy of equine digits, but the observations cannot simply be extrapolated to in vivo conditions and their dynamic characteristics.

This method may be applied to living organisms. In fact, the implantation of bony linked trihedrons may be performed on living animals. Bone pins have been implanted on horses [50] as well as on human beings $[36,37,43]$. A $6 \mathrm{~mm}$ canal drilled through the bone, including bone cortex, and Steinmann pins does not affect the locomotion of sound horses [49]. Trihedrons could be screwed on such sticks before the test sessions.

This article was devoted to the computation of small 3D angles like axial rotation as well as collateromotion. This method can be helpful to improve the understanding of the ætiology of joint injuries and articular pain as well as the indications of corrective hoof shoeing. It is not specific to the horse and the algorithms described may be directly adapted to the study of articular movements in other species. Moreover the publications in human biomechanics suffered from a lack of homogeneity till the standardisation committee of the ISB expressed its recommendations in 1995. The analysis of the application of this method in the horse may 
favour the homogeneity of further studies in animal biomechanics.

\section{ACKNOWLEDGMENTS}

This study was partly financially supported by the Service des Haras. The authors would like to thank J.P. Valette and T. Piolet for helping them in the statistical analysis of the results.

\section{REFERENCES}

[1] Abdel-Aziz H., Karara H., Direct linear transformation from comparator coordinates in objectspace coordinates in close-range photogrammetry, Proc. Congress Am. Soc. Photogrammetry, Urbana, Illinois (1971) 1-18.

[2] Andrews J.G., On the specification of joint configurations and motions, J. Biomech. 17 (1984) 155-158.

[3] Apkarian J., Naumann S., Cairns B., A threedimensional kinematic and dynamic model of the lower limb, J. Biomech. 22 (1989) 143-155.

[4] Areblad M., Nigg B.M., Ekstrand J., Olsson K.O., Ekström H., Three-dimensional measurement of rearfoot motion during running, J. Biomech. 3 (1990) 933-940.

[5] Back W., Schamhardt H.C., Savelberg H.H.C.M. van den Bogert A.J., Bruin G., Hartman W., Barneveld A., How the horse moves: 1. Significance of graphical representations of equine forelimb kinematics, Equine Vet. J. 27 (1995) 31-38.

[6] Balch O., Butler D., Hoof balance and lameness: improper toe length, hoof angle and mediolateral balance, Compendium on Continuing Education for the Practicing Veterinarian 17 (1995) 12751283.

[7] Barone R., Anatomie comparée des mammifères domestiques - Tome 2 : arthrologie et myologie, Ed Vigot, Paris, 1989.

[8] Blankevoort L., Huiskes R., de Lange A., The envelope of passive knee joint motion, J. Biomech. 21 (1988) 705-720.

[9] Bull A.M.J., Amis A.A., Knee joint motion: description and measurement, Proc. Inst. Mech. Eng. 212 (1998) 357-372.

[10] Bushe T., Turner T.A., Poulos P.W., Harwell N.M., The effect of hoof angle on coffin, pastern and fetlock joint angles, Am. Assoc. Equine Pract. Proceedings 33 (1987) 729-738.

[11] Cappozzo A., Gait analysis methodology, Hum. Mov. Sci. 3 (1984) 27-50

[12] Cappozzo A., Catani F., Leardini A., Benedetti M.G., Della Croce U., Position and orientation of bones during movement: experimental artefacts, Clin. Biomech. 11 (1996) 90-100.
[13] Caudron I., Grulke S., Farnir F., Aupaix R., Serteyn D., Radiographic assessment of equine interphalangeal joints asymmetry: articular impact of phalangeal rotations (Part 1), J. Vet. Med. A 45 (1998) 319-325

[14] Chao E.Y.S, Justification of triaxial goniometer for the measurement of joint rotation, J. Biomech. 13 (1980) 989-1006.

[15] Chen L., Armstrong C.W., Raftopoulos D.D., An investigation on the accuracy of three dimensional space reconstruction using the direct linear transformation technique, J. Biomech. 27(1994) 493-500.

[16] Chèze L., Fregly B.J., Dimnet J., A solidification procedure to facilitate kinematic analyses based on video system data, J. Biomech. 28 (1995) 879884.

[17] Cochran S.L., The treatment of distal interphalangeal joint synovitis in sport horses, Am. Assoc. Equine Pract. Proceedings 36 (1990) 281-288.

[18] Cole G.K., Nigg B.M., Ronsky J.L., Yeadon M.R., Application of the Joint Coordinate System to three-dimensional joint attitude and movement representation: a standardization proposal, J. Biomech. Eng. 115 (1993) 344-349.

[19] Crisco J.J., Chen X., Panjabi M.M., Wolfe S.W., Optimal marker placement for calculating the instantaneous center of rotation, J. Biomech. 27 (1994) 1183-1187.

[20] Degueurce C., Dietrich G., Pourcelot P., Denoix J.M., A three-dimensional kinematic technique for evaluation of horse locomotion in outside conditions, Med. Biol. Eng. Comput. 34 (1996) 249252.

[21] Degueurce C., Pourcelot P., Audigié F., Denoix J.M., Geiger D., Variability of the limb joint patterns of sound horses at trot, Equine Vet. J. suppl. 23 (1997) 89-92.

[22] Denoix J.M., Etude biomécanique de la région phalangienne chez le cheval, Compte-rendu de la $11^{\mathrm{e}}$ journée d'étude du CEREOPA (centre d'étude et de recherche sur l'économie et l'organisation des productions animales), Paris, 6 mars 1985, pp. 60-75.

[23] Denoix J.M., Etude biomécanique de la main du Cheval: extensométrie des rayons métacarpo-phalangiens et surfaces articulaires de contact, Ph.D. thesis, Univ. Claude Bernard Lyon 1, 1987.

[24] Denoix J.M., Examen radiographique de l'articulation interphalangienne proximale, Pratique Vétérinaire Equine (1990) 59-72.

[25] Denoix J.M., Biomécanique interphalangienne dans les plans sagittal et frontal, Proceedings du Congrès de médecine et de chirurgie équine et du Congrès de l'association mondiale des vétérinaires équins, Genève, 3 (1993) 44-49.

[26] Denoix J.M., Functional anatomy of the equine interphalangeal joints, Am. Assoc. Equine Pract. Proceedings 45 (1999) 174-177. 
[27] Dyson S., Lameness due to pain associated with the distal interphalangeal joint 45 cases, Equine Vet. J. 23 (1991) 128-135.

[28] Fioretti S., Cappozzo A., Lucchetti L., Joint kinematics, in: Three-dimensional analysis of human locomotion, Wilay \& Sons Ed, Chichester, 1997, pp. 173-189.

[29] Grood E.S., Suntay W.J., Comment on "justification of triaxial goniometer for the measurement of joint rotation", J. Biomech. 14 (1981) 653655.

[30] Grood E.S., Suntay W.J., A joint coordinate system for the clinical description of three-dimensional motions: application to the knee, J. Biomech. Eng. 105 (1983) 136-144.

[31] Hertsch B., Beerhues U., Der Wendeschmerz als Symptom bei der Lamheitsuntersuchung des Pferdes - Pathomorphologische, röntgenologische und kinische Untersuchungen, Pferdeheilkunde 4 (1988) 15-22.

[32] Kadaba M.P., Ramakrishnan H.K., Wooten M.E., Gainey J., Gorton G., Cochran G.V.B., Repeatibility of kinematic, kinetic, and electromyographic data in normal adult gait, J. Orthop. Res. 7 (1989) 849-860.

[33] Kettelkamp D.B., Johnson R.J., Schmidt G.L., Chao E.Y., Walker M., An electrogoniometric study of knee motion in normal gait, J. Bone Joint Surg. Am. 52 (1970) 775-790.

[34] Kinzel G.L., Gutkowski L.J., Joint models, degrees of freedom, and anatomical motion measurement, J. Biomech. Eng. 105 (1983) 55-62.

[35] Lafortune M.A., Cavanagh P.R., Sommer H.J., Kalenak A., Three-dimensional kinematics of the human knee during walking, J. Biomech. 25 (1992) 347-357

[36] Lamoreux L.W., Kinematic measurements in the study of human walking, Bull. Prosthet. Res. 10 (1971) 3-84.

[37] Levens A.S., Inman V.T., Blosser J.A., Transverse rotation of the segments of the lower extremity in running, J. Bone Jt Surg., Am. 30 (1948) 859-872

[38] McDiarmid A.M., Distal interphalangeal joint lameness in a horse associated with damage to the insertion of the lateral collateral ligament, Equine Veterinary Education 10 (1998) 114-118.

[39] Pourcelot P., Audigié F., Degueurce C., Denoix J.M., Geiger D., Cinématique en extérieur: une méthode d'enregistrement et de traitement des films cinématiques, Arch. Int. Physiol. Biochimie 104 (1996) 637.

[40] Pourcelot P., Audigié F., Degueurce C., Denoix J.M., E.K.A.S., an equine kinematic analysis system for clinical gait analysis, J. Equine Vet. Sci. 17 (1997) 482.
[41] Ramakrishnan H.K., Kadaba M.P., On the estimation of joint kinematics during gait, J. Biomech. 24 (1991) 969-977.

[42] Ratzlaff M., Grant B. D., The use of electrogoniometry and cinematography in the diagnosis and evaluation of forelimb lamenesses, Am. Assoc. Equine Pract. Proceedings (1985) 183198.

[43] Reinshmidt C., van den Bogert A.J., Nigg B.M., Lundberg A., Murphy N., Effects of skin movement on the analysis of skeletal knee joint motion during running, J. Biomech. 30 (1997) 729-732.

[44] Selvik G., Roentgen stereogrammetry: a method for the study of the kinematics of the skeleton system, Acta Orthop. Scand. suppl. 232 (1989) $1-51$.

[45] Skalli W., Lavaste F., Descrimes J.L., Quantification of three-dimensional vertebral rotations in scoliosis: what are the true values?, Spine 20 (1995) 546-553.

[46] Small C.F., Bryant J.T., Pichora D.R., Rationalization of kinematic descriptors for three-dimensional hand and finger motion, J. Biomed. Eng. 14 (1992) 133-141.

[47] Swanson T.D., Degenerative disease of the proximal interphalangeal (pastern) joint in performance horses, Am. Assoc. Equine Pract. Proceedings 34 (1988) 393-397.

[48] Townsend M.A., Izak M., Jackson R.W., Total motion knee goniometry, J. Biomech. 10 (1977) 183-193.

[49] van Weeren P.R., Skin displacement in equine kinematic gait analysis, Ph.D. thesis, Rijksuniversiteit te Utrecht, 1989.

[50] van Weeren P.R., Barneveld A., A technique to quantify skin displacement in the walking horse, J. Biomech. 19 (1986) 879-883.

[51] van Weeren P.R., van den Bogert A.J., Barneveld A., A quantitative analysis of skin displacement in the trotting horse, Equine Vet. J. suppl. 9 (1990) 101-109.

[52] Vernizeau M., Lefebvre Y., Minfelde R., Jenny J.Y., Lavaste F., Opto-electronic analysis of in vitro knee kinematic: a preliminary study, Proc. World Congress on Medical Physics and Biomedical Engineering, Nice, France (1997) 196.

[53] Wilson A.M., Seelig T.J., Shield R.A., Silverman B.W., The effect of hoof imbalance on point of force application in the horse, Equine Vet. J. 30 (1998), 540-545.

[54] Woltring H.J., Representation and calculation of 3-D joint movement, Hum. Mov. Sci. 10 (1991) 603-616.

[55] Wu G., Cavanagh P.R., ISB recommendations for standardization in the reporting of kinematic data, J. Biomech. 28 (1995) 1257-1261. 